


\title{
Allgemeine Brefめiळte
}

\author{
Dex \\ Meligions formen \\ bet \\ beibnifden $\mathfrak{B d}$ der.
}

Darsenedit

Bos

\%. ซ.

Boeiter ebeil.

Sexlin:

Berlag oon Bett uno Comp.

1888. 


\section{Die}

\section{Pieligions: Onfteme}

Dex

Şellenen in ifree gefdidtlid)en Entwidelung

biz auf bie malebonifaje Beit.

DargefeIt

Don

3. ร. $\varepsilon+n \boldsymbol{n}$

Serlin:

Berlag oon Beit uno Comp.

1888. 
